\section{Clocks in the Paris Observatory}

$\mathrm{T}$ HE Bulletin Horaire du Bureau International de l'heure of February gives an account of the running of the clocks at the Paris Observatory during 1935.

It is interesting to note that a British clock, the Shortt free pendulum No. 44, has given the best performance of the year, and indeed this particular clock has put up a year's performance which is probably unequalled by other clocks of the same make. During 1935, the monthly mean values of the daily rate varied only from $-0.367 \mathrm{~s}$ per day to $-0 \cdot 377^{\mathrm{s}}$ per day, and the accidental variation of the daily rate from the mean value for the month was only $0.0017^{\mathrm{s}}$. In computing the last figure, the Paris astronomers took account of the variation in apparent clock-rate due to long period nutation, the principal term as regards clock-rate in which has an amplitude of $\pm 0.003^{s}$ per day and a period of six months. It has hitherto been considered in Paris unnecessary to take this term into account in discussing clock-rates.

The best Shortt clock at Greenwich is No. 3, which has twice given a straight run, so far as could be determined, over a period of three months, that is to say, that during the three months the clock error was not observed to depart from the value corresponding to the mean rate. A clock error greater than $0.01^{s}$ should be detected. It has been habitual to take account of both long and short period nutation at Greenwich in discussing clock performances.

To clear up misunderstandings about this subject, it is as well to state here that wireless time signals are sent out on mean time, which is unaffected by either long- or short-period nutation. The sidereal time contains nutation, so that the error and rate of a mechanically perfect clock show the nutation when compared with true sidereal time. In discuss. ing the mechanical performance of the clock, it is ideally necessary to remove nutation from the sidereal time, which is what one determines by transit observations. The corrections for nutation have always been made in computing mean time for wireless signals from transit observations, but in discussing sidereal clock rates, determined from transit observations, long-period nutation has sometimes been ignored, as its effect on the rate (but not on the error) is small.

\section{Educational Topics and Events}

CAMBridge.-The following grants towards the expenses of expeditions have been made from the Worts Fund : $£ 50$ to F. E. Kemp, an expedition to the Great Barrier Reef ; $£ 50$ to N. E. Odell, to study glacier movements in the Eastern Himalayas ; $£ 30$ to T. T. Steiger, to study the effects of European civilisation upon the life of a native tribe in Uganda; $£ 40$ to G. E. Daniel, for archæological purposes in the Western Mediterranean; $£ 37$ to J. S. Turner, for an ecological survey of the oak woods of the Killarney region; $£ 40$ to Miss C. K. Rickardo, to study the ecology of a small lake in Rhodesia ; $£ 50$ to M. G. M. Pryor, to study the ecology and distribution of the Trichoptera (caddis flies) of the mountains of northern Jugoslavia.

The General Board recommends that the following additional University teaching offices be established from October 1, 1936 : a readership in the Department of Geology, a University demonstratorship in soil science in the Department of Agriculture, a University demonstratorship in the Department of Botany (subject to the requirement that the person appointed shall act as curator of the Herbarium and the Botanical Museum), a University lectureship in the Department of Zoology, a University demonstratorship in the Department of Zoology (subject to the requirement that the person appointed shall act as senior curator of the Museum of Zoology), a University lectureship in the Department of Physiology (temporarily replacing a demonstratorship).

At Downing College, Dr. J. Hammond has been elected to a non-stipendiary fellowship.

London.-Prof. J. G. Semple has been appointed as from October 1, 1936 , to the University chair of mathematics tenable at King's College. Since 1930 he has been professor of mathematics in the Queen's University, Belfast.

The title of reader in electrical engineering in the University has been conferred on Mr. W. J. John, in respect of the post held by him at Queen Mary College.

It has been resolved that, on the occasion of the centenary celebrations of the University this year, degrees should be conferred honoris causa on thirteen British and six foreign distinguished men, including Sir William Bragg, Mr. S. A. Courtauld, Sir Joseph Larmor, Dr. J. W. Mackail, Sir George Newman, Sir Charles Peers and Mr. H. G. Wells; and Prof. Albert Einstein, Prof. Johan Hjort and Prof. Max Planck.

The following doctorates have been conferred:- D.Litt. on Mr. C. E. M. Joad, of Birkbeck College; D.Sc. in chemistry on Mr. F. D. Miles, of the Imperial College (Royal College of Science) ; D.Sc. in engineering on Mr. S. J. Davies, University reader at King's College.

Dr. C. D. Ellis has been appointed as from October 1 to the Wheatstone chair of physies tenable at King's College. Since 1923 he has been lecturer in natural science at Trinity College and lecturer in the Department of Physics in the University of Cam. bridge.

The London (Royal Free Hospital) School of Medicine for Women has received an anonymous gift of $£ 11,000$ to endow "The Free Woman's Lectureship in Clinical Medicine". Dr. Una Ledingham, assistant physician, Royal Free Hospital, has been appointed to the lectureship. The Aldrich Blake travelling scholarship (1936) has been awarded to Miss Geraldine Barry, assistant surgeon, Royal Free Hospital.

DR. J. M. GULlaND has been appointed to the Sir Jesse Boot chair of chemistry in University College, Nottingham, in succession to Prof. F. S. Kipping, who is to retire at the end of the session. Dr. Gulland is at present reader in biochemistry, University of London, and senior assistant in biochemistry in the Lister Institute. Prof. W. H. McMillan, head of the Department of Mining and Fuels of the College, has submitted his resignation on being appointed to the James A. Hood chair of mining in the University of Edinburgh and the Heriot Watt College, Edinburgh. Prof. McMillan was the first occupant of the chair of mining established at Nottingham in 1911. 